\title{
The efficacy and safety of silodosin for the treatment of ureteral stones: a systematic review and meta-analysis
}

\author{
Diandong Yang, Jitao Wu, Hejia Yuan and Yuanshan Cui
}

\begin{abstract}
Background: To evaluate the efficacy and safety of silodosin as a medical expulsive therapy for ureteral stones by means of a systematic review and meta-analysis.

Methods: We searched MEDLINE, EMBASE and the Cochrane Controlled Trials Register to identify randomized controlled trials (RCTs) of silodosin in the treatment of ureteral stones. The reference lists of retrieved studies were also investigated.

Results: Six RCTs, including 916 participants and comparing silodosin with controls, were used in the meta-analysis. Silodosin was superior to controls in terms of stone expulsion rate, the primary efficacy end point in all six RCTs (odds ratio [OR] for expulsion 2.16, $95 \%$ confidence interval $[\mathrm{Cl}] 1.62$ to $2.86, p<0.00001$ ). Silodosin was also more effective for secondary efficacy end points; the stone expulsion time (standardized mean difference [SMD] $-3.66,95 \%$ $\mathrm{Cl}-6.61$ to $-0.71 ; p=0.01)$ and analgesic requirements (SMD $-0.89,95 \% \mathrm{Cl}-1.19$ to $-0.60 ; p<0.00001$ ) were significantly reduced compared with those of controls. Other than the incidence of abnormal ejaculation, which was higher in the silodosin groups (OR 2.84, $95 \% \mathrm{Cl} 1.56$ to 5.16, $p=0.0006)$, few adverse effects were observed.
\end{abstract}

Conclusion: This meta-analysis indicates silodosin is an effective and safe treatment option for ureteral stones with a low occurrence of side effects.

Keywords: Silodosin, Ureteral stones, Meta-analysis, Randomized controlled trial

Abbreviations: $\mathrm{RCT}$, Randomized controlled trial; OR, Odds ratio; Cl, Confidence interval; SMD, Standardized mean difference; MET, Medical expulsive therapy; a1A-AR, a1A-adrenoceptor

\section{Background}

Urolithiasis is a multifactorial disease that is common in daily urological practice, and is also a substantial public health problem. After urinary tract infections and pathologic conditions of the prostate [1], urolithiasis is the third most common disease of the urinary tract, with an estimated prevalence of $2-3 \%$ and a lifetime recurrence rate of approximately $50 \%[2,3]$. To date, minimally invasive therapies, such as extracorporeal shock wave lithotripsy, ureterolithotripsy and percutaneous nephrolithotomy have proved to be effective treatments in many cases. Nevertheless, these procedures are expensive and are not without risk [4].

\footnotetext{
* Correspondence: doctorcuiys@163.com

Jitao Wu co-first author.

Department of Urology, Yantai Yuhuangding Hospital Affiliated to Medical College of Qingdao University, NO.20 East Yuhuangding Road, 264000 Yantai, China
}

C 2016 Yang et al. Open Access This article is distributed under the terms of the Creative Commons Attribution 4.0 International License (http://creativecommons.org/licenses/by/4.0/), which permits unrestricted use, distribution, and reproduction in any medium, provided you give appropriate credit to the original author(s) and the source, provide a link to the Creative Commons license, and indicate if changes were made. The Creative Commons Public Domain Dedication waiver (http://creativecommons.org/publicdomain/zero/1.0/) applies to the data made available in this article, unless otherwise stated. can be used in most cases, and is becoming more popular as a result of advances in pharmacological therapy, which can reduce symptoms and facilitate stone expulsion [5, 6]. For example, medical expulsive therapy (MET) using $\alpha$-adrenoceptor antagonists has emerged as an alternative strategy for the initial management of small distal ureteral stones [7].

Silodosin is a novel highly selective $\alpha 1 \mathrm{~A}$-adrenoceptor ( $\alpha 1 \mathrm{~A}-\mathrm{AR})$ blocker: in vitro its $\alpha 1 \mathrm{~A}-\mathrm{to}-1 \mathrm{~B}$ binding ratio is extremely high (162:1), suggesting that it has the potential to reduce dynamic neurally mediated smooth muscle relaxation in the ureter, while minimizing undesirable effects on blood pressure regulation [8].

The goal of this study was to perform a meta-analysis to evaluate the efficacy and safety of silodosin as a MET for ureteral stones to help address some of the current controversies over its use for this indication. 


\section{Methods}

\section{Search strategy}

MEDLINE (1966 to Jan 2015), EMBASE (1974 to Jan 2015) and the Cochrane Controlled Trials Register databases were searched to identify randomized controlled trials (RCTs) of silodosin in the treatment of ureteral stones; we also searched the reference lists of the retrieved studies. The following search terms were used: "silodosin"; "ureteral stones"; and "randomized controlled trial".

\section{Inclusion criteria and trial selection}

Randomized controlled trials that met the following criteria were included: (1) the study design included treatment with silodosin; (2) the study provided accurate data that could be analyzed, including the total number of subjects and the values of each outcome measured; and (3) the full text of the study could be accessed. When the same study was published in more than one journal or in different years, the most recent publication was used for the meta-analysis. If the same group of researchers studied a group of subjects with multiple experiments, then each study was included. A flow diagram of the study selection process is presented in Fig. 1.

\section{Quality assessment}

The quality of the retrieved RCTs was assessed using the Jadad scale [9]. All identified RCTs were included in the meta-analysis, regardless of the quality score. The methodological quality of each study was assessed according to the means of allocation of participants to the arms of the study, the concealment of allocation procedures, blinding and data loss due to attrition. The studies were then classified qualitatively according to the guidelines published in the Cochrane Handbook for Systematic Reviews of Interventions v.5.1.0 [10]. Each study was rated according to these quality assessment criteria, and assigned to one of the three following quality categories: A, if all quality criteria were adequately met the study was deemed to have a low risk of bias; $\mathrm{B}$, if one or more of the quality criteria was only partially met or was unclear the study was deemed to have a moderate risk of bias; or $\mathrm{C}$, if one or more of the criteria was not met or not included the study was deemed to have a high risk of bias. Differences were resolved by discussion among the authors.

\section{Data extraction}

The following information was collected for each study: (1) the name of the RCT; (2) the study design and sample size; (3) the therapy that the patients received; (4) the country in which the study was conducted; and (5) data including the stone expulsion rate, stone expulsion time, analgesics required and incidence of adverse events, including abnormal ejaculation in male participants.

\section{Statistical analysis and meta-analysis}

The meta-analysis of comparable data was carried out using RevMan v.5.1.0 (Cochrane Collaboration, Oxford, UK) [10]. We estimated the relative risk for dichotomous outcomes and the standardized mean difference (SMD) for continuous outcomes pooled across studies by using the DerSimonian and Laird random-effects model [11]. The corresponding $95 \%$ confidence interval (CI) was calculated, if the result of analysis showed $p>0.05$, we considered the studies homogeneous and so chose a fixed-effect model for meta-analysis; otherwise, a random-effect model was used. We quantified inconsistency using the $I^{2}$ statistic, which describes the proportion of heterogeneity across studies that is not due to chance, thus describing the extent of true inconsistency in results across trials [12]. $I^{2}<25 \%$ reflects a small amount of inconsistency and $I^{2}>50 \%$ reflects significant inconsistency.

\section{Results}

\section{Characteristics of the individual studies}

The database search produced 114 articles that could have been included in our meta-analysis. Based on the inclusion and exclusion criteria, 99 articles were excluded after reading the titles and abstracts of the articles; nine articles were not RCTs. In all, six articles [13-18], reporting data from three RCTs that compared silodosin with tamsulosin, two RCTs that compared silodosin with placebo and one RCT that compared silodosin with naftopidil were included in the analysis (Fig. 1). The baseline characteristics of the studies included in our meta-analysis are listed in Table 1.

\section{Quality of the individual studies}

Two of the six RCTs were double-blinded, and included descriptions of the randomization processes used. Three RCTs included a power calculation to determine the optimal sample size (Table 2). The quality of all identified studies was categorized as A or B, and the final Jadad score for each study ranged from 3 to 5 points (Table 2). A funnel plot suggested there was no bias (Fig. 2).

\section{Efficacy}

\section{Stone expulsion rate}

Six RCTs with 916 participants (457 in the silodosin groups and 459 in the control groups, Fig. 3) reported stone expulsion rate as the primary outcome measure. According to our analysis, no heterogeneity was found between the trials $(P=0.39)$ (Fig. 3$)$, and a fixed-effects model was thus chosen for the analysis. Silodosin 


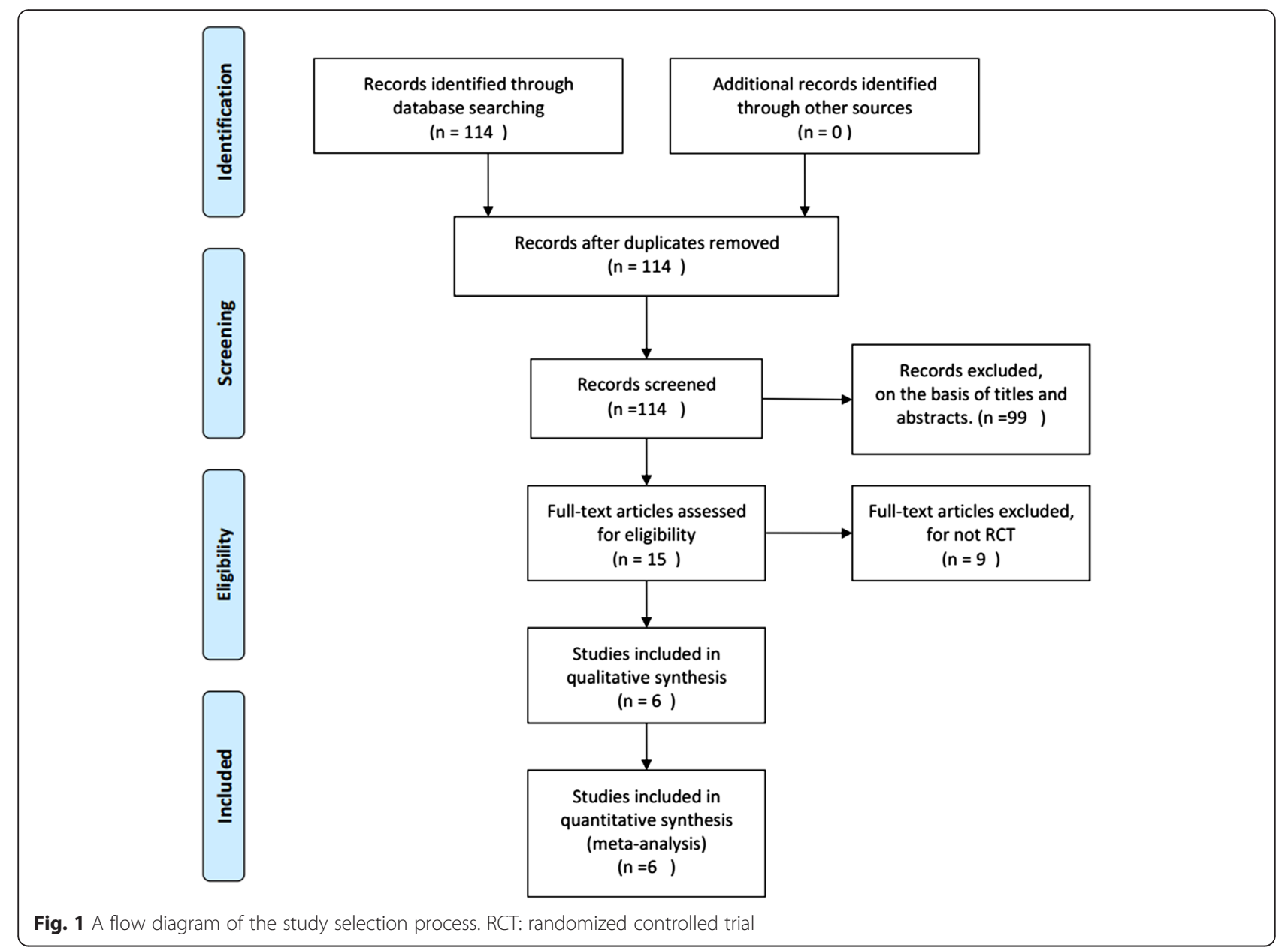

showed a significantly superior stone expulsion rate compared with controls (OR 2.16, 95 \% CI 1.62 to 2.86; $p<0.00001)$.

\section{Stone expulsion time}

Four RCTs with 541 participants (270 in the silodosin groups and 271 in the control groups, Fig. 3) reported stone expulsion times as a secondary outcome. According to our analysis, heterogeneity was found between the trials $(P=0.0001)$. A random-effects model was chosen for the analysis. The stone expulsion time was significantly shorter in the silodosin groups than controls (SMD -3.66, $95 \% \mathrm{CI}-6.61$ to $-0.71 ; p=0.01)$.

\section{Analgesia required}

Two of the RCTs (consisting of 367 participants, with 185 in the silodosin groups and 182 in the control groups, Fig. 3) reported the analgesics required during stone expulsion. According to our analysis, no heterogeneity was found between the trials $(P=0.85)$. A fixedeffects model was chosen for the analysis. Expulsion using silodosin was associated with a significantly lower analgesic requirement than that in controls (SMD -0.89 , $95 \% \mathrm{CI}-1.19$ to $-0.69 ; p<0.00001)$.

\section{Side effects and safety Abnormal ejaculation}

Six RCTs with 916 participants (457 in the silodosin groups and 458 in the control groups, Fig. 3) reported the incidence of abnormal ejaculation (Fig. 4). The effect size for the purposes of meta-analysis was denoted as the OR. According to our analysis based on a fixed-effects model, no heterogeneity was found between the trials $(P=0.47)$. The pooled estimate of OR was 2.84 (95\% CI 1.56 to 5.16, $p=0.0006)$. This suggests that abnormal ejaculation was more common among patients treated with silodosin than among control-treated patients.

\section{Subgroup analysis}

We divided the included studies into three groups on the basis of the treatment given to the control groups: tamsulosin, naftopidil or inactive placebo. According to 
Table 1 Study and patient characteristics

\begin{tabular}{|c|c|c|c|c|c|c|c|c|c|}
\hline \multirow[t]{2}{*}{ Study } & \multirow{2}{*}{$\begin{array}{l}\text { Therapy in } \\
\text { experimental } \\
\text { group }\end{array}$} & \multirow{2}{*}{$\begin{array}{l}\text { Therapy in } \\
\text { control group }\end{array}$} & \multirow[t]{2}{*}{ Country } & \multicolumn{2}{|l|}{ Sample size } & \multirow{2}{*}{$\begin{array}{l}\text { Administration } \\
\text { method }\end{array}$} & \multirow{2}{*}{$\begin{array}{l}\text { Duration of } \\
\text { treatment }\end{array}$} & \multirow[t]{2}{*}{ Dosage } & \multirow[t]{2}{*}{ Stone location and size range } \\
\hline & & & & experimental & Control & & & & \\
\hline $\begin{array}{l}\text { Itoh Y } \\
2011\end{array}$ & silodosin & blank control & Japan & 95 & 92 & Oral & $8 w k$ & $8 \mathrm{mg} / \mathrm{d}$ & $\begin{array}{l}\text { symptomatic unilateral ureteral } \\
\text { calculi of less than } 10 \mathrm{~mm}\end{array}$ \\
\hline $\begin{array}{l}\text { Tsuzaka Y } \\
2011\end{array}$ & silodosin & naftopidil & Japan & 35 & 39 & Oral & $6 w k$ & $8 \mathrm{mg} / \mathrm{d}$ & $\begin{array}{l}\text { symptomatic } \leq 10 \mathrm{~mm} \text { ureteral } \\
\text { stones }\end{array}$ \\
\hline $\begin{array}{l}\text { Guptas S } \\
2013\end{array}$ & silodosin & tamsulosin & India & 50 & 50 & Oral & 4 wk & $8 \mathrm{mg} / \mathrm{d}$ & $\begin{array}{l}\text { unilateral, uncomplicated middle } \\
\text { or lower ureteral stones } \leq 10 \mathrm{~mm}\end{array}$ \\
\hline $\begin{array}{l}\text { Dell'Atti L } \\
2014\end{array}$ & silodosin & tamsulosin & Italy & 68 & 68 & Oral & $3 w k$ & $8 \mathrm{mg} / \mathrm{d}$ & $\begin{array}{l}\text { single, unilateral, radiopaque, } \\
\text { proximal ureteral stone } \\
\text { (range } 4-10 \mathrm{~mm} \text { in size) }\end{array}$ \\
\hline $\begin{array}{l}\text { Sur RL } \\
2014\end{array}$ & silodosin & placebo & USA & 119 & 120 & Oral & $4 w k$ & $8 \mathrm{mg} / \mathrm{d}$ & $\begin{array}{l}\text { unilateral ureteral calculus of } \\
4-10 \mathrm{~mm}\end{array}$ \\
\hline $\begin{array}{l}\text { Kumar S } \\
2015\end{array}$ & silodosin & tamsulosin & India & 90 & 90 & Oral & 4 wk & $8 \mathrm{mg} / \mathrm{d}$ & $\begin{array}{l}\text { distal ureteric stones of size } \\
5-10 \mathrm{~mm}\end{array}$ \\
\hline
\end{tabular}

our analysis, no heterogeneity was found between the trials $(P>0.05)$; therefore, we chose a fixed-effects model for the analysis. Stone expulsion rates were significantly higher in those treated with silodosin compared with tamsulosin (OR 1.65, $95 \%$ CI 1.12 to $2.43 ; p=0.01$ ), naftopidil (OR 2.83, $95 \%$ CI 1.80 to $4.45 ; p<0.00001$ ) or inactive placebo (OR 3.36, $95 \%$ CI 1.13 to 9.96; $p=0.03$, Fig. 5).

We further divided the included studies into two groups according to stone location: proximal or distal. According to our analysis, no heterogeneity was found between the trials $(P>0.05)$; therefore, a fixed-effects model was chosen. Stone expulsion rates were significantly higher in those treated with silodosin compared with control in spite of the stone location. (proximal OR 2.1, $95 \%$ CI 1.12 to $3.92 ; p=0.02$ or distal OR $2.53,95 \%$ CI 1.61 to $3.99 ; p<0.00001$, Fig. 6).

\section{Discussion}

The introduction of more effective drugs has seen significant improvements in the medical management of ureteral stones. The likelihood of a ureteral stone passing depends on several factors, which include the stone size and location, and the condition of the ureter [19]. The stimulation of the $\alpha 1-\mathrm{AR}$ in the ureter increases the force of ureteric contraction and the frequency of ureteric peristalsis. Blockade of the $\alpha 1-\mathrm{AR}$ inhibits basal tone, reduces peristaltic amplitude and frequency, and decreases intraluminal pressure while increasing the rate of fluid transport and the chances of stone expulsion. Expression of the $\alpha 1 \mathrm{~A}$ - and $\alpha 1 \mathrm{D}-\mathrm{AR}$ subtypes is greater in the distal ureter [20]. Silodosin is a highly selective $\alpha 1 \mathrm{~A}-\mathrm{AR}$ blocker, and it has been demonstrated in vitro that silodosin's $\alpha 1 \mathrm{~A}-$ to- $1 \mathrm{~B}$ binding ratio is extremely high (162:1).

Our meta-analysis found that silodosin $8 \mathrm{mg} /$ day for 3-8 weeks is superior to controls (tamsulosin $0.4 \mathrm{mg} /$ day, naftopidil $50 \mathrm{mg} /$ day or inactive placebo) in improving the stone expulsion rate, reducing the stone expulsion time and analgesic requirements. According to our analysis, no heterogeneity was found between the trials, allowing us to use a fixed-effects model for the analysis. We may therefore conclude that silodosin $8 \mathrm{mg} /$ day treats stones more

Table 2 Quality assessment of individual study

\begin{tabular}{|c|c|c|c|c|c|c|c|c|}
\hline Study & $\begin{array}{l}\text { Allocation sequence } \\
\text { generation }\end{array}$ & $\begin{array}{l}\text { Allocation } \\
\text { concealment }\end{array}$ & Blinding & $\begin{array}{l}\text { Loss to } \\
\text { follow-up }\end{array}$ & $\begin{array}{l}\text { Calculation of } \\
\text { sample size }\end{array}$ & Statistical analysis & Level of quality & $\begin{array}{l}\text { Jadad } \\
\text { Score(5-point) }\end{array}$ \\
\hline Itoh Y 2011 & B & B & $A$ & 6 & $\mathrm{NO}$ & Student's t-test & B & 3 \\
\hline Tsuzaka Y 2011 & $B$ & B & $A$ & 10 & $\mathrm{NO}$ & Student's t-test & B & 3 \\
\hline Guptas S 2013 & $A$ & B & $A$ & 0 & $\mathrm{NO}$ & Student's t-test & $A$ & 4 \\
\hline Dell'Atti L 2014 & $B$ & $A$ & $A$ & 3 & YES & Student's t-test & A & 4 \\
\hline Sur RL 2014 & $A$ & $A$ & $A$ & 6 & YES & Wilcoxon test & A & 5 \\
\hline Kumar S 2015 & $A$ & A & $A$ & 6 & YES & chi-square test & $A$ & 5 \\
\hline
\end{tabular}

A - all quality criteria met (adequate): low risk of bias. B - one or more of the quality criteria only partly met (unclear): moderate risk of bias $\mathrm{C}$ - one or more criteria not met (inadequate or not used): high risk of bias 


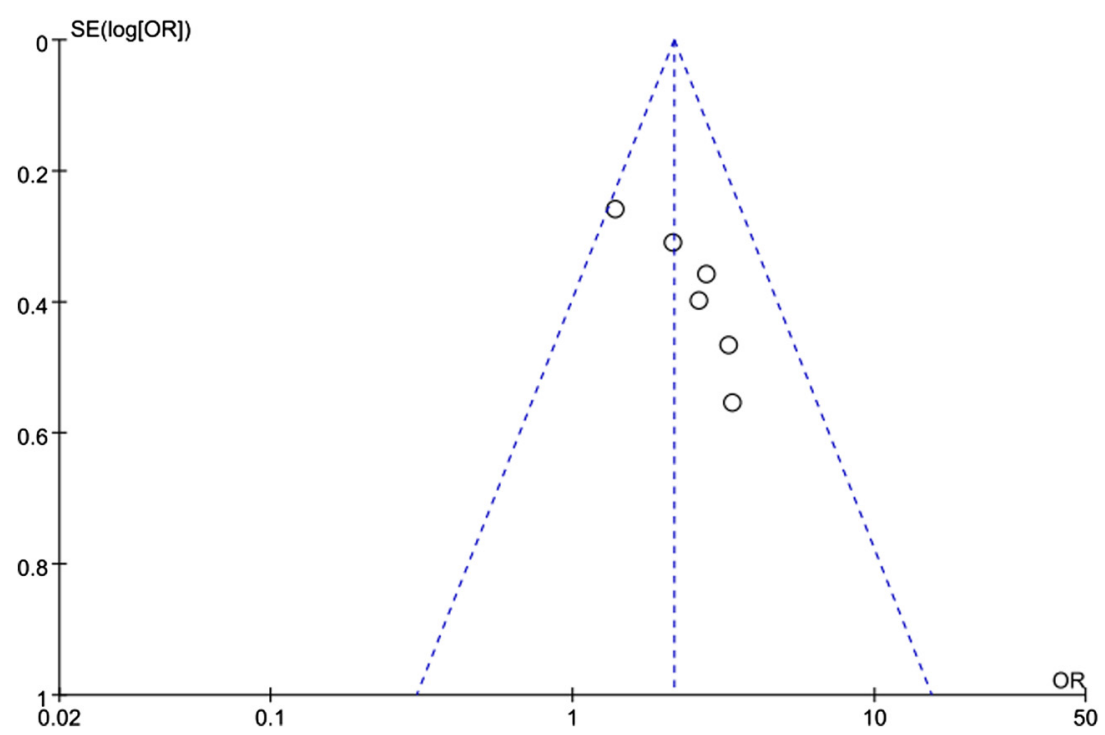

Fig. 2 Funnel plot of the studies represented in our meta-analysis. OR: odds ratio, SE: standard error

effectively than tamsulosin $0.4 \mathrm{mg} /$ day, naftopidil $50 \mathrm{mg} /$ day or placebo. Our subgroup analysis showed that stone expulsion rates were significantly higher in those treated with silodosin compared with those treated with a control, regardless of stone location. It is worth noting that stone expulsion rates ranged from $57.7 \%$ to $80.9 \%$ in cases involving proximal ureteral stones, and $69.8 \%$ to $93.8 \%$ in distal ureteral stones. Therefore, it seems that the stone expulsion rate for distal ureteral stones is higher than for proximal ureteral stones. Stone size has been identified as

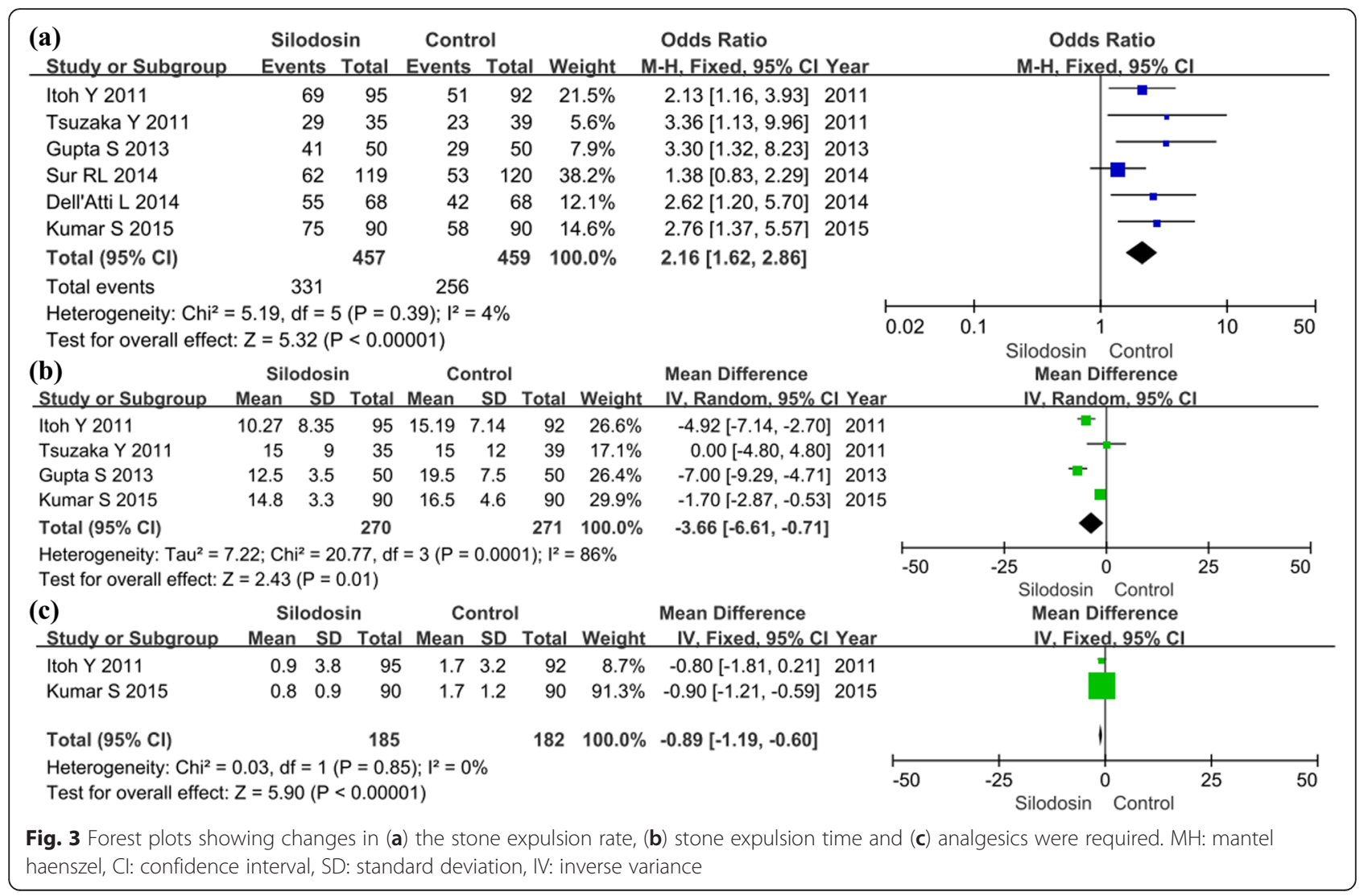




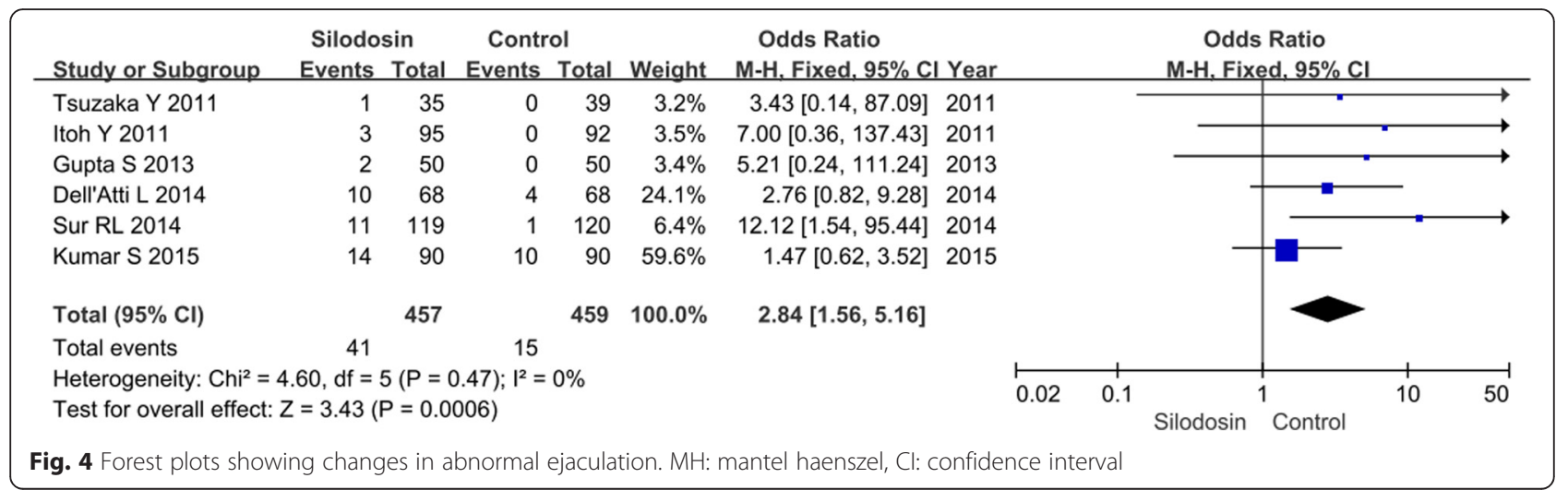

an important predictive factor for expulsion: the trials we chose examined those $\leq 10 \mathrm{~mm}$ in diameter, so we cannot draw any conclusions about the role of silodosin in the treatment of larger ureteral calculi.

The $\alpha 1 \mathrm{~A} / \mathrm{D}$ selective AR-blocker tamsulosin is recognized as a safe and effective drug that also enhances spontaneous passage of distal ureteral stones $\leq 10 \mathrm{~mm}$ in diameter [21]. Recent studies have demonstrated that the $\alpha 1 \mathrm{~A}$ subtype plays the most important role in mediating phenylephrine-induced contraction of the isolated human ureter [22]. Kobayashi et al. found that silodosin enhanced noradrenaline-induced contraction of the human ureter more than the selective $\alpha 1 \mathrm{D}-\mathrm{AR}$ antagonist BMY-7378 [23]. The mechanism of action of silodosin presumably includes blockade of the $\alpha$-adrenergic receptors, thereby relaxing the ureter and potentially providing a spasmolytic effect [24].

Our meta-analysis suggests that there is a higher incidence of retrograde ejaculation in patients treated with silodosin than active or inactive controls. The incidence of side effects was similar to that reported by other authors [25]. Nonetheless, retrograde ejaculation does not appear to be particularly troublesome, and only a small proportion of participants enrolled in clinical studies

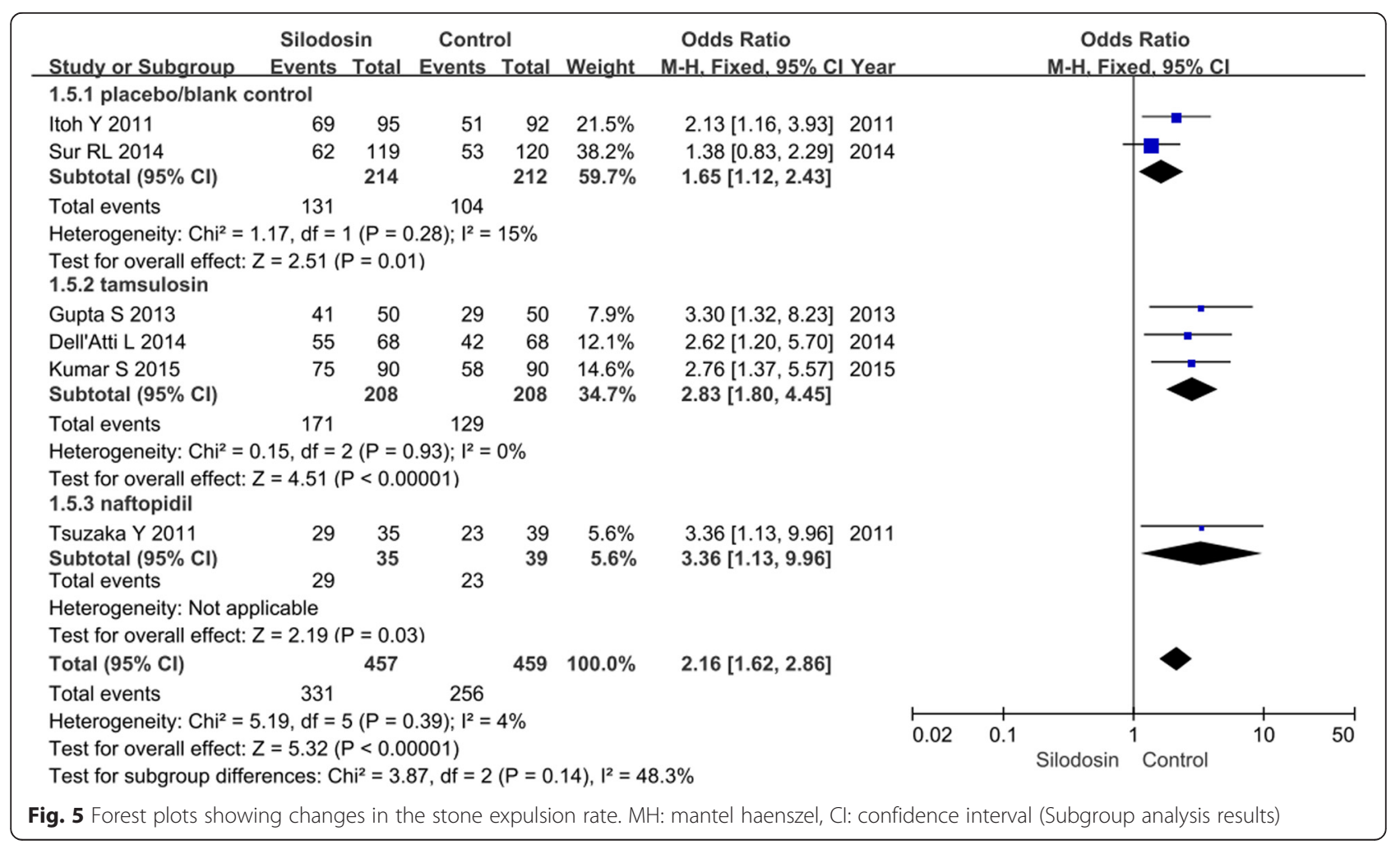




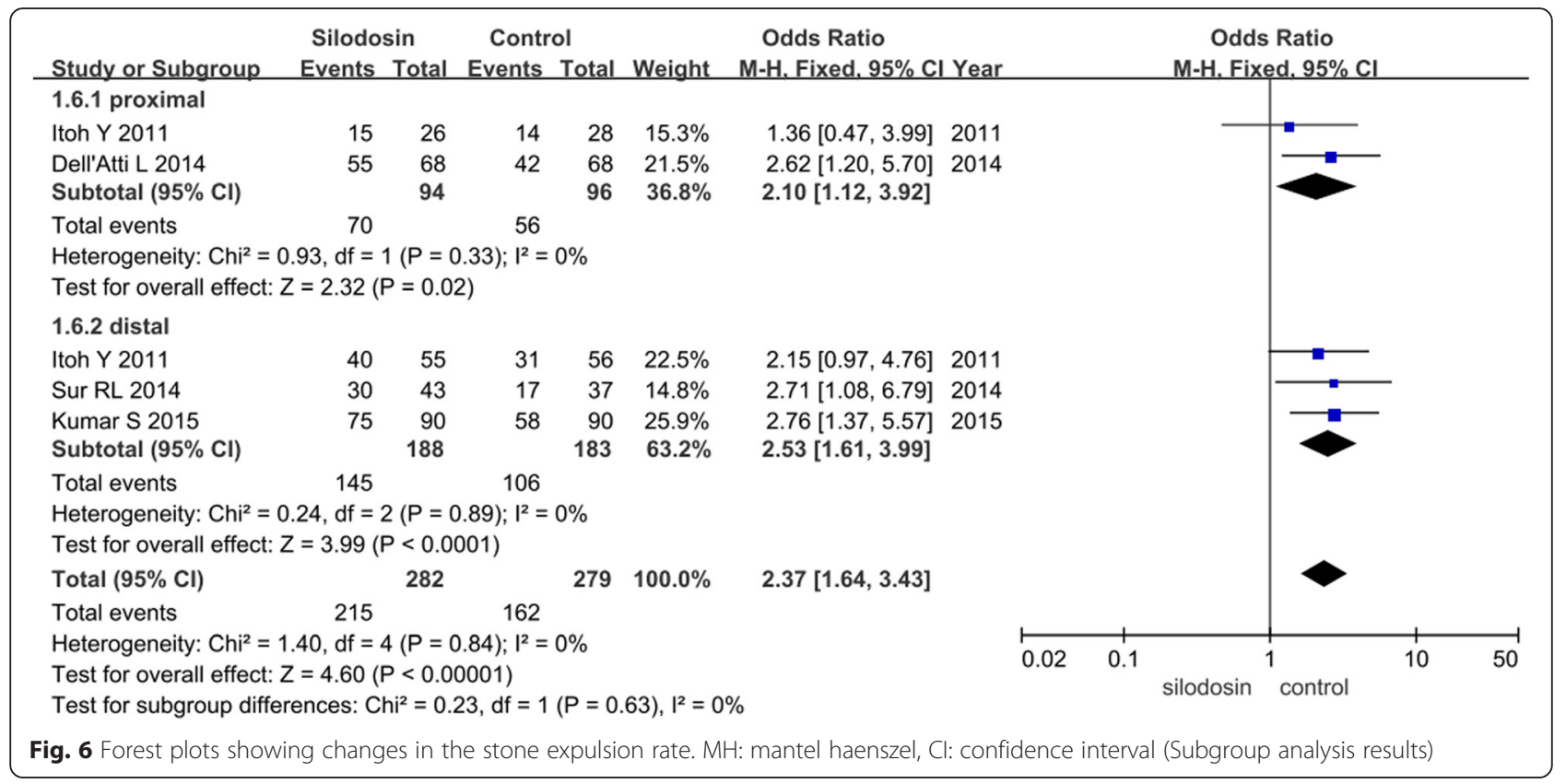

who report this adverse effect discontinued treatments because of it [26]. Furthermore, retrograde ejaculation resolves completely within a few days of discontinuing treatment [26]. Silodosin appears to relax the smooth muscles of the lower urinary tract and the genital tract enough to induce retrograde ejaculation, reflected in the finding that patients who had the greatest relief from lower urinary tract symptoms had a higher likelihood of retrograde ejaculation. This observation suggests that retrograde ejaculation is an indirect indicator of the extent of the smooth muscle relaxation that silodosin induces. Other than retrograde ejaculation, the type and incidence of adverse events reported by those taking silodosin were similar to those taking tamsulosin, naftopidil or an inactive control. Besides, Imperatore $\mathrm{V}$ et al. conducted a retrospectively controlled study demonstrated that MET with silodosin is associated with a lower incidence of side effects related to peripheral vasodilation but an higher incidence of retrograde ejaculation when compared to tamsulosin [27].

Our meta-analysis was based on data collected entirely from RCTs that we considered to be at low risk of bias. This suggests that our findings could be sufficiently sound to inform everyday clinical practice. Importantly, however, the number of included studies was small and there were a variety of control groups; therefore, a certain amount of clinical heterogeneity seems inevitable. Furthermore, we cannot account for the possible influence of unpublished studies, which could have introduced an unrecognized bias into our analysis. The longer-term efficacy and safety of silodosin cannot therefore be extrapolated from our findings. More high-quality trials with larger sample sizes are needed to establish fully the role of silodosin in the treatment of distal ureteral stones.

\section{Conclusions}

This meta-analysis indicates silodosin is an effective and safe treatment option for ureteral stones with a low occurrence of side effects.

\section{Acknowledgement}

We thank Edanz Group (liwenbianji) for assisting in the preparation of this manuscript.

\section{Authors' contributions}

CYS designed the research, interpreted the data and revised the paper. YDD, WTT, and YHJ performed the data extraction, carried out the meta-analysis and drafted the paper. All of the authors approved the submitted and final versions.

\section{Competing interests}

The authors declare that they have no competing interests.

Ethics approval and consent to participate

All analyses were based on previous published studies, thus no ethical approval and patient consent are required.

Received: 9 May 2015 Accepted: 17 May 2016

Published online: 27 May 2016

\section{References}

1. Stefanos PJ, Michael C. Trussa, Treatment strategies of ureteral stones. EAU-EBU Up-date Series. 2006:4:184-90.

2. Sakhaee K, Maalouf NM, Sinnott B. Clinical review. Kidney stones 2012: pathogenesis, diagnosis, and management. J Clin Endocrinol Metab. 2012; 97:1847-60.

3. Bihl $\mathrm{G}$, Meyers $\mathrm{A}$. Recurrent renal stone disease-advances in pathogenesis and clinical management. Lancet. 2011:358:651-6.

4. Dellabella M, Milanese G, Muzzonigro G. Randomized trial of the efficacy of tamsulosin, nifedipine and phloroglucinol in medicalexpulsive therapy for distal ureteral calculi. J Urol. 2005;174:167-72. 
5. Borghi L, Meschi T, Amato F, Novarini A, Giannini A, Quarantelli C, et al. Nifedipine and methylprednisolone in facilitating ureteral stone passage: a randomized, double-blind, placebo-controlled study. J Urol. 1994;152:1095-8.

6. Porpiglia F, Destefanis P, Fiori C, Fontana D. Effectiveness of nifedipine and deflazacort in the management of distal ureter stones. Urology. 2000;56:579-82.

7. Tzortzis V, Mamoulakis C, Rioja J, Gravas S, Michel MC, de la Rosette JJ. Medical expulsive therapy for distal ureteral stones. Drugs. 2009;69:677-92.

8. Tatemichi S, Kobayashi K, Maezawa A, Kobayashi M, Yamazaki Y, Shibata N. a1-Adenoceptor subtype selectivity and organ specificity of silodosin (KMD-3213). Yakugaku Zasshi. 2006;126:209-16.

9. Jadad AR. Randomised controlled trials. London: BMJ Publishing Group; 1998

10. Higgins JPT, Green S, editors: Cochrane handbook for systematic reviews of interventions, v.5.1 [updated March 2011]. Cochrane Collaboration Web site. http://handbook.cochrane.org/.

11. DerSimonian R, Laird N. Meta-analysis in clinical trials. Control Clin Trials. 1986;7:177-88

12. Higgins JP, Thompson SG, Deeks JJ, Altman DG. Measuring inconsistency in meta-analyses. BMJ. 2003;327:557-60.

13. Itoh Y, Okada A, Yasui T, Hamamoto S, Hirose M, Kojima Y. Efficacy of selective a1A adrenoceptor antagonist silodosin in the medical expulsive therapy for ureteral stones. Int J Urol. 2011;18:672-4.

14. Tsuzaka Y, Matsushima H, Kaneko T, Yamaguchi T. Homma Y. Naftopidil vs silodosin in medical expulsive therapy for ureteral stones: a randomized controlled study in Japanese male patients. Int J Urol. 2011;18:792-5.

15. Gupta S, Lodh B, Singh AK, Somarendra K, Meitei KS, Singh SR. Comparing the efficacy of tamsulosin and silodosin in the medical expulsion therapy for ureteral calculi. J Clin Diagn Res. 2013;7:1672-4.

16. Dell'Atti L. Silodosin versus Tamsulosin as medical expulsive therapy for distal ureteral stones: a prospective randomized study. Urologia. 2014;82:54-7.

17. Sur RL, Shore N, L'Esperance J, Knudsen B, Gupta M, Olsen S, et al. Silodosin to Facilitate Passage of Ureteral Stones: A Multi-institutional, Randomized, Double-blinded, Placebo-controlled Trial. Eur Urol. 2014;67:959-64.

18. Kumar S, Jayant K, Agrawal MM, Singh SK, Agrawal S, Parmar KM. Role of tamsulosin, tadalafil, and silodosin as the medical expulsive therapy in lower ureteric stone: a randomized trial (a pilot study). Urology. 2015:85:59-63.

19. Sun X, He L, Ge W, Lv J. Efficacy of selective alpha1D-blocker naftopidil as medical expulsive therapy for distal ureteral stones. J Urol. 2009:181:1716-20.

20. Griwan MS, Singh SK, Paul H, Pawar DS, Verma M. The efficacy of tamsulosin in lower ureteral calculi. Urol Ann. 2010;2:63-6.

21. De SM, Autorino R, Di LG, Damiano R, Giordano D, Cosentino L. Medical expulsive treatment of distal-ureteral stones using tamsulosin: a single-center experience. J Endourol. 2006;20:12-6

22. Sasaki S, Tomiyama Y, Kobayashi S, Kojima Y, Kubota Y, Kohri K. Characterization of a1-adrenoceptor subtypes mediating contraction in human isolated ureters. Urology. 2011;77:762.e13-17.

23. Kobayashi S, Tomiyama Y, Hoyano Y, Yamazaki Y, Kusama H, Itoh Y. Gene expressions and mechanical functions of a1-adrenoceptor subtypes in mouseureter. World J Urol. 2009:27:775-80.

24. Preminger GM, Tiselius HG, Assimos DG, Alken P, Buck C, Gallucci M, Knoll T, Lingeman JE, Nakada SY, Pearle MS, et al. 2007 guideline for the management of ureteral calculi. J Urol. 2007;178(6):2418-34.

25. Cui Y, Zong H, Zhang Y. The efficacy and safety of silodosin in treating BPH: a systematic review and meta-analysis. Int Urol Nephrol. 2013;44:1601-9.

26. Montorsi F. Profile of Silodosin. Eur Urol Suppl. 2010;491-495.

27. Imperatore V, Fusco F, Creta M, Di Meo S, Buonopane R, Longo N, et al. Medical expulsive therapy for distal ureteric stones: tamsulosin versus silodosin. Arch Ital Urol Androl. 2014:86:103-7.

\section{Submit your next manuscript to BioMed Central and we will help you at every step:}

- We accept pre-submission inquiries

- Our selector tool helps you to find the most relevant journal

- We provide round the clock customer support

- Convenient online submission

- Thorough peer review

- Inclusion in PubMed and all major indexing services

- Maximum visibility for your research

Submit your manuscript at www.biomedcentral.com/submit
Biomed Central 